\title{
Ultrastructural study of two subtypes of gastric adenoma
}

\author{
M MURATANI, T NAKAMURA, G-I NAKANO, K MUKAWA \\ From the First Department of Surgery, Gunma University School of Medicine, Maebashi, Japan
}

SUMMARY An ultrastructural study was performed to identify any differences in fine detail between type III and IV gastric polyps, which seem to differ from each other because they have different histological features and malignant potential. Clear ultrastructural differences were found, implicating microvilli, mucous granules, interdigitations, ribosomes, mitochondria and nuclei. Although these two subtypes have often been grouped together as borderline lesions or adenomas, the findings imply that they should be treated as essentially different.

Gastric polyps have been classified into four histopathological subtypes. ${ }^{\prime 2}$ Type I polyps are solitary and pedunculated, and consist mainly of hyperplastic ducts similar to gastric foveolae. These ducts are lined with high columnar epithelial cells with clear cytoplasm and spindle-shaped nuclei at the base of the cells. Although the gland ducts are irregular with branching, winding, and dilatation which forms cysts, no cellular dysplasia can be recognised.

Type II polyps are usually multiple and distributed in the distal fundal mucosa of the stomach. Most of them have pinkish dimples at their tips. The central portion of the polyp corresponding to the dimple has a superficial erosion and consists of hyperplastic regenerative epithelial cells. Type II polyps are assumed to be derived from excessive and persistent healing of a pre-existing erosion. Types I and II are considered to be hyperplastic rather than neoplastic polyps because of the absence of dysplasia and their extremely low malignant potential.

On the other hand, types III and IV polyps are regarded as adenomas because of their dysplasia and malignant potential. Type III polyps comprise a double layered structure, the superficial layer of which is composed of dysplastic epithelium (fig la). This type has a relatively low malignant potential $(5 \cdot 9 \%)$. Macroscopically and histologically, type IV polyps are similar to those of a colonic adenoma and they have a malignant potential $(33 \cdot 3 \%)$. The malignant potential

Accepted for publication 3 November 1988 of each subtype of gastric polyp is shown in table $1 .^{2}$

Submucosal invasion or lymph node metastases were not seen in 18 of the 19 cases of focal carcinoma. ${ }^{2}$ In two cases cellular and structural atypia were sufficiently severe and similar to those observed in invasive carcinoma that we considered them to be focal carcinomas. The criteria for malignant change described by Nakamura are as follows:

(i) Malignant and benign tissue should be present in the same polyp.

(ii) The benign part should be large enough to prove that the precursor is a benign polyp.

(iii) Malignancy should be diagnosed, not only where invasion of the lamina propria has occurred but also when cellular and architectural atypia are sufficiently severe without invasion.

Nakamura has emphasised that types III and IV polyps are essentially different entities, ${ }^{2}$ and although these two subtypes have often been grouped together as borderline lesions in Japan, ${ }^{34}$ that they should be clearly differentiated and treated differently. ${ }^{5}$

Several authors, however, ${ }^{3467}$ have indicated that there is a gradual transformation from type III to type IV polyp; they do not recognise types III and IV polyps as essentially different. Furthermore, there has been a tendency in Japan to diagnose type IV polyps as differentiated adenocarcinomas. Type IV polyps with focal cancer have been regarded not as benign adenomas with a focal carcinoma, but adenocarcinomas.

An ultrastructural study was performed to throw some light on the true nature of type III and IV polyps, which have previously been studied only by light microscopy. 


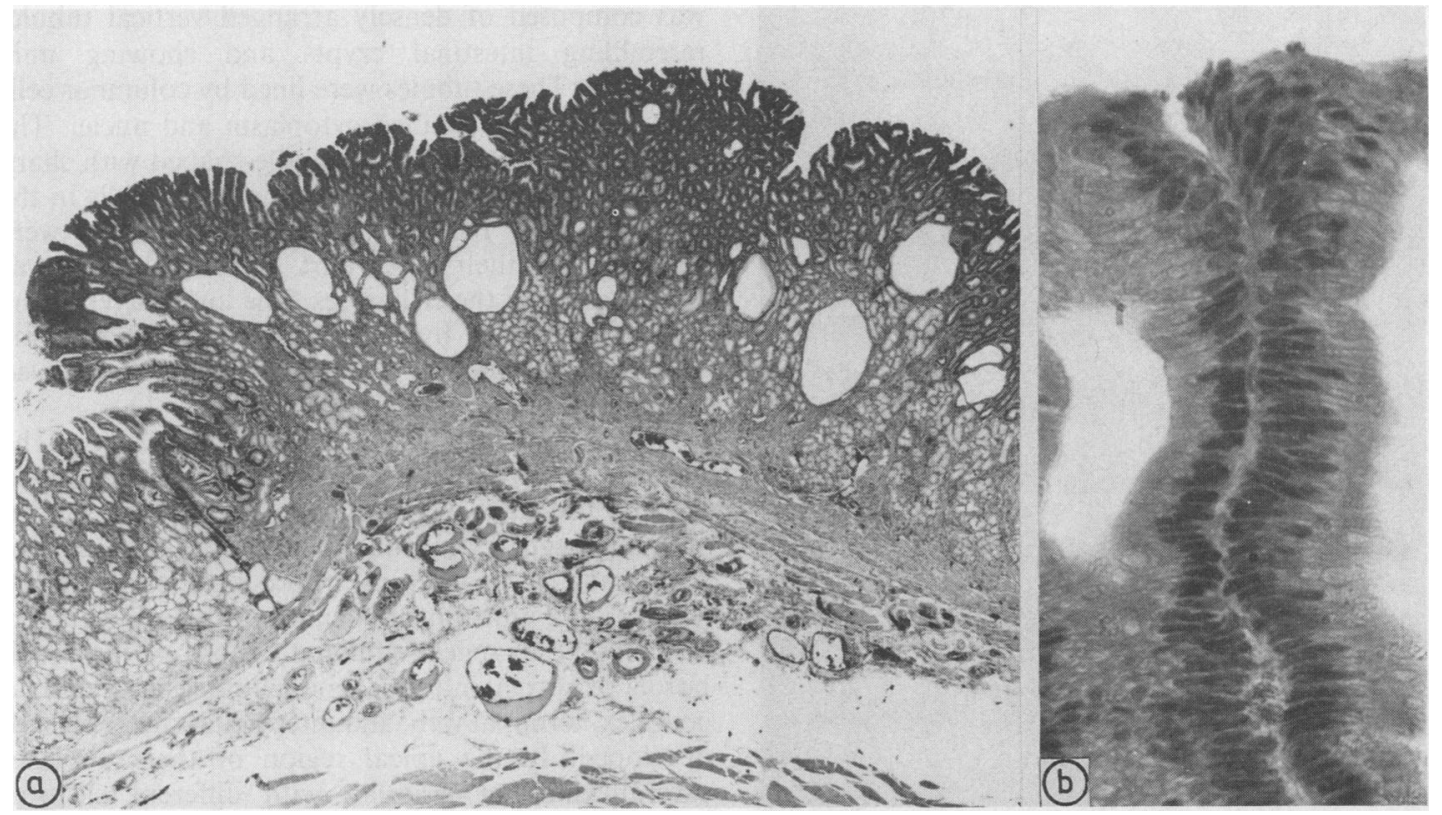

Fig 1 (a) Type III polyp showing characteristic two layer structure. Superfacial layer is composed of densely arranged vertical tubules and deep layer consists of hyperplastic pyloric glands and multiple cysts. (b) Glands of upper layer are lined by columnar cells showing mild dysplasia. Cytoplasm and nuclei are darkly stained. Nuclei are elongated and spindle-shaped.

(Haematoxylin and eosin.)

\section{Material and methods}

Tissue samples were obtained at operation or endoscopically from patients with gastric polyps or gastric cancers attending Gunma University Hospital between 1975 and 1984. They comprised seven type III polyps from six patients, six type IV polyps from five patients, eight gastric carcinomas (differentiated type) from eight patients and normal gastric mucosae obtained from the resected stomachs of five cases of gastric carcinoma.

The histological features of the type IV polyp have been classified into three patterns: tubular, tubulovillous, and villous. ${ }^{2}$ The six type IV polyps comprised a tubular pattern in three and a villous pattern in the

Table 1 Focal cancers in gastric polyps in each Nakamura subtype*

\begin{tabular}{|c|c|c|c|c|}
\hline \multirow{2}{*}{$\begin{array}{l}\text { Subtypes } \\
\text { Type I } \\
\text { Type II } \\
\text { Type III } \\
\text { Type IV }\end{array}$} & \multicolumn{2}{|c|}{ No of polyps } & \multicolumn{2}{|l|}{$\begin{array}{l}\text { No with focal } \\
\text { cancers (\%) }\end{array}$} \\
\hline & $\left.\begin{array}{r}335 \\
169 \\
68 \\
39\end{array}\right]$ & $\begin{array}{l}275 \\
\text { patients }\end{array}$ & $\begin{array}{l}2(0.6) \\
0 \\
4(5.9) \\
13(33.3)\end{array}$ & $\begin{array}{r}\text { Hyperplastic } \\
\text { polyp } \\
\text { Adenoma }\end{array}$ \\
\hline
\end{tabular}

*Includes non-invasive cases in which there was cellular or architectural atypia of a severity equivalent to that of carcinoma. remainder. Eight gastric carcinomas (three papillary and five tubular adenocarcinomas) were also studied to identify differences between them and type IV polyps.

Specimens for electron microscopy were obtained from areas close to the centre of the polyps. They were fixed in $2.5 \%$ glutaraldehyde for two hours and postfixed with $1.0 \%$ osmium tetroxide adjusted to $\mathrm{pH}$ 7.4 with $1 / 15 \mathrm{M}$ phosphate buffer for one hour, and then dehydrated with increasing concentrations of ethanol and embedded in Epon-Araldite mixture. Thick sections stained with toluidine blue were carefully orientated during light microscopic examinations. The ultrathin sections cut on an ultramicrotome MT-2B were stained with uranyl acetate and lead citrate, and when necessary, with methenamine silver, ${ }^{8}$ to identify mucous granules. They were then examined in a Hitachi transmission electron microscope H-700 with an accelerating potential of $100 \mathrm{kV}$.

\section{Results}

\section{TYPE III POLYPS}

These polyps were usually sessile with an uneven surface, resembling flower beds or mountain ranges. Histologically these polyps showed a characteristic two layer structure. The superficial layer of the polyp . 


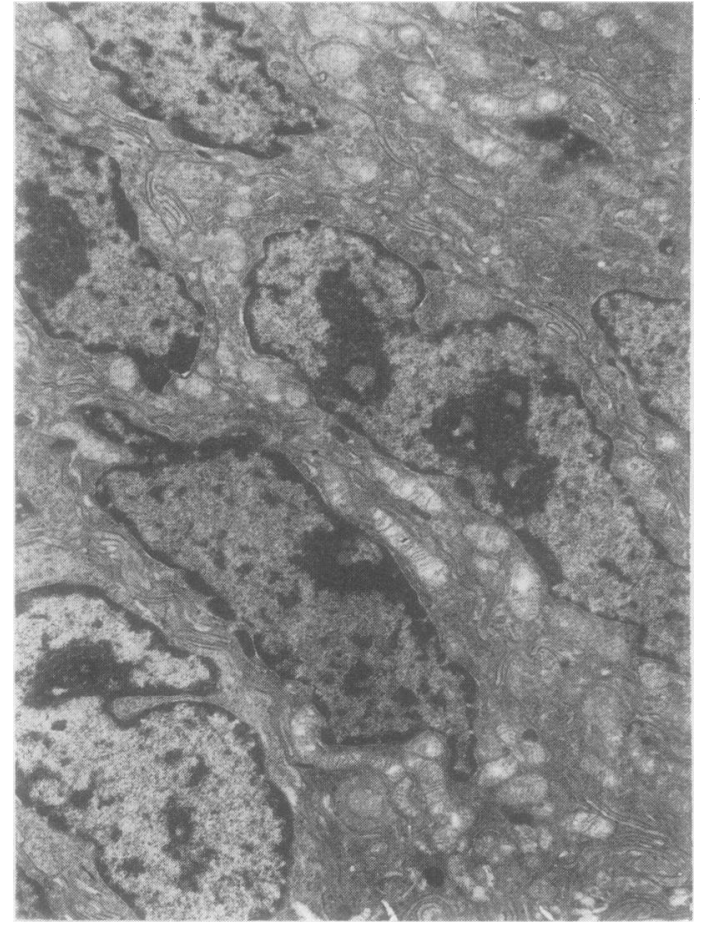

Fig 2 Nuclei of type III polyp cells are elongated and spindle-shaped (as seen by light microscopy) with irregular contour and rich in heterochromatin. was composed of densely arranged vertical tubules resembling intestinal crypts and showing mild dysplasia. These tubules were lined by columnar cells with very darkly stained cytoplasm and nuclei. The nuclei were elongated and spindle-shaped with sharp ends (figs 1a-b). There were some goblet cells in the upper part of the glands, and Paneth cells were recognised in their lower part. A brush border was seen at some of the cell apices. The lower layer of the polyp consisted of hyperplastic pyloric glands, some showed cystic change. These glands and cysts showed no dysplasia.

At the electron microscopic level the cells of the upper layer were columnar and the nuclei were located basally. The latter were elongated and spindle-shaped with an irregular contour as observed by light microscopy and were rich in heterochromatin (fig 2). Microvilli of uniform length and width were regularly and closely arranged, similar to those of the brush border of normal intestinal epithelium. The junctional complex, terminal web, and interdigitations were well developed. In the apical region of the cytoplasm several kinds of granules with different electron densities were observed (fig 3). The methenamine silver stain indicated that they were mucous granules (fig 4). The number of mucous granules was highly variable from cell to cell. There were an average

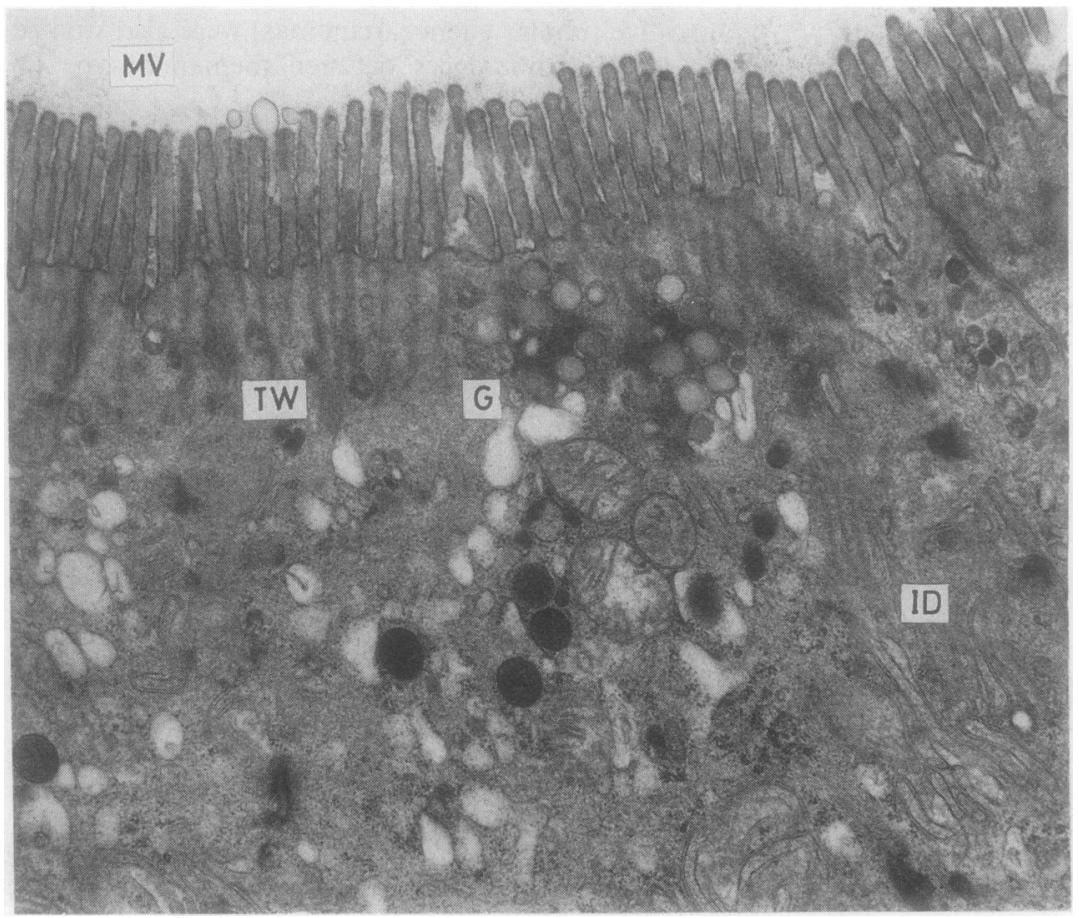

Fig 3 Microvilli (MV) of uniform length and width are regularly and closely arranged in type III polyp. Junctional complex, terminal web $(T W)$, and interdigitation (ID) are well developed. In apical region of cytoplasm, several kinds of granule $(G)$ with varying electron density can be seen. 


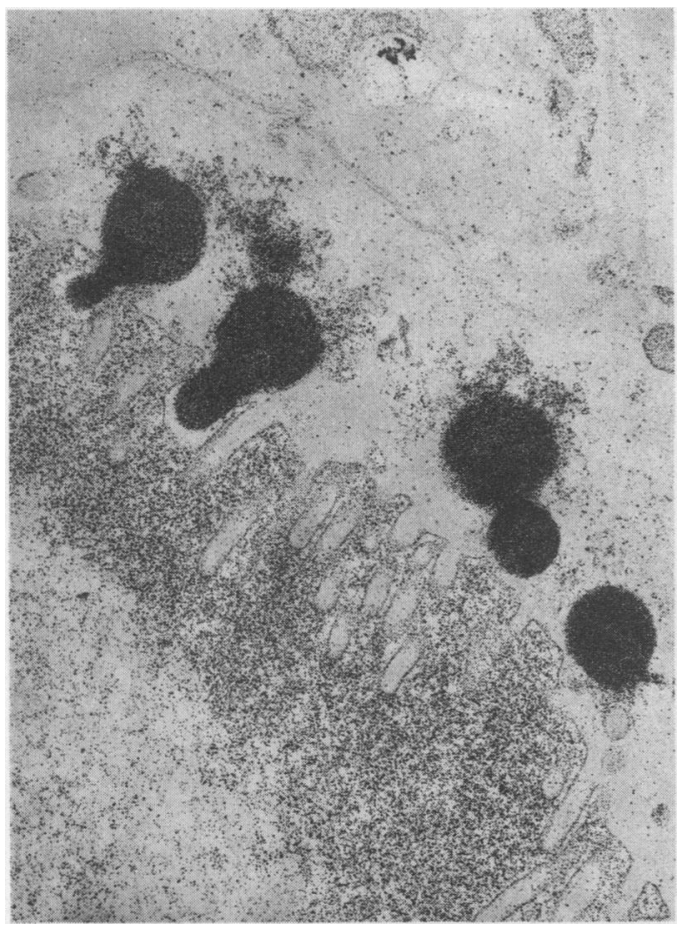

Fig 4 Several kinds of granule observed in a type III polyp cell are clearly stained by methenamine silver method. number of short or long rod-shaped mitochondria and ribosomes compared with normal intestinal epithelium.

\section{TYPE IV POLYPS}

Type IV polyps were macroscopically similar to adenomas of the colon. They were either sessile or pedunculated and their surfaces were finely lobulated with intercommunicating clefts. Epithelial cells showed mild, moderate, or severe dysplasia. Various grades of nuclear stratification were observed, but not to the extent seen in carcinoma. Nuclei were mostly elongated, oval-shaped, and showed a regular contour. Nucleoli were often prominent (figs 5a, b).

At the ultrastructural level, nuclei were large and oval-shaped with a smooth outline and were rich in euchromatin. These findings corresponded with the light microscopic findings (fig 6). Sparse microvilli were irregularly arranged and variable in length and width. In many cells a terminal web was not observed clearly. Development of interdigitation was also very poor. The cytoplasm had a few small mucous granules, many oval mitochondria, numerous free ribosomes and some polyribosomes (fig 7). Numerous nuclear bodies were observed (fig 6). There were no clear ultrastructural differences between tubular and villous type IV polyps.

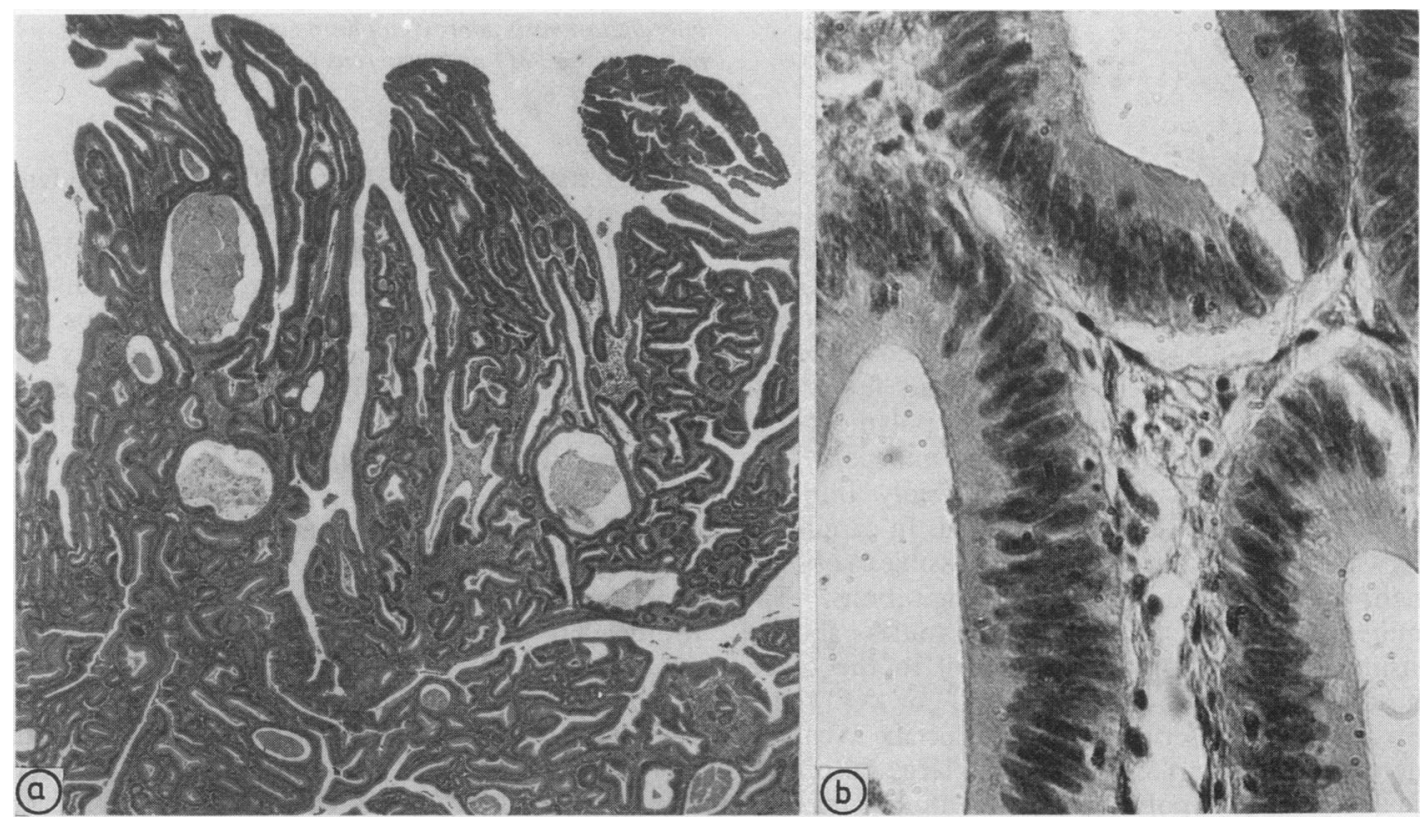

Fig 5 (a) Histological detail of type IV polyp shows tubular adenoma similar to those of colonic adenomas. (Haematoxylin and eosin.) (b) Epithelial cells of type IV polyp are columnar in shape and nuclei are mostly elongated, oval-shaped, with blunt ends and regular contour. 


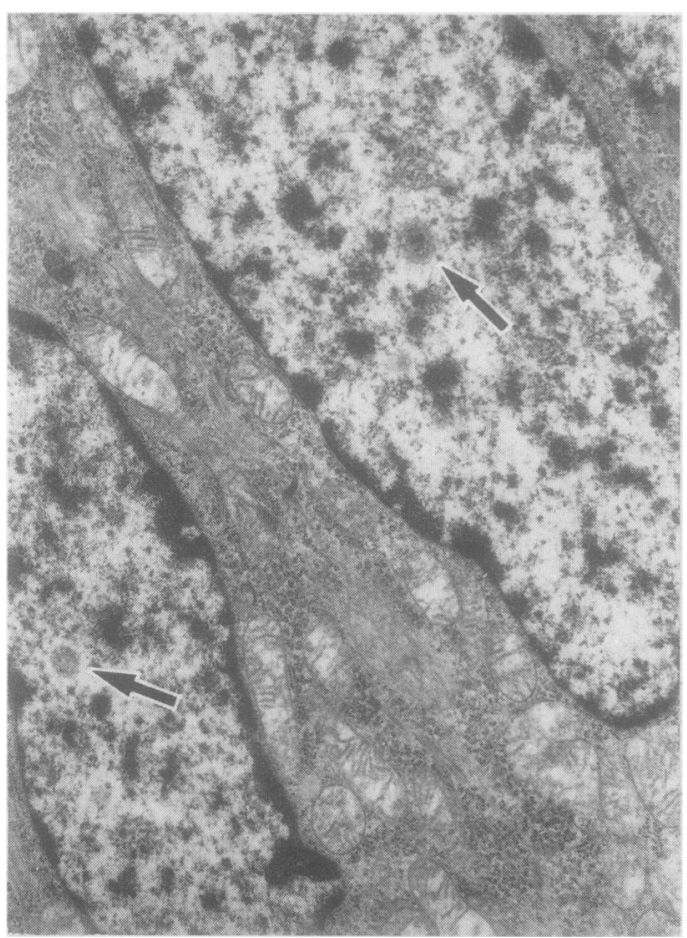

Fig 6 Nuclei of type IV polyp cells are large and ovalshaped with a smooth outline and rich in euchromatin. Many nuclear bodies (arrows) are observed in the nuclei.

ADENOCARCINOMA (DIFFERENTIATED TYPE)

Electron microscopy showed that the carcinoma cells were cuboidal or polygonal in shape and contained large nuclei with prominent nucleoli. The nuclear shape was similar to the type IV polyp, but size was more variable. Nuclear bodies were encountered in most cases. Some carcinoma cells had few or no microvilli, but others had many polymorphous microvilli. Abnormal microvilli with unusually long core filaments which penetrated deeply into the cytoplasm were occasionally observed. In carcinoma cells with no microvilli it was rarely possible to observe junctional complexes and interdigitations. The number and size of mucous granules showed considerable variation from one cell to the other. Unusual mucous granules with a " $C$ " or " $O$ " shape were sometimes observed; they were specific to carcinoma cells. The cytoplasm had many large mitochondria and numerous polyribosomes. Annulate lamellae were encountered only in carcinoma cells (fig 8).

Papillary and tubular adenocarcinoma had similar electron microscopic appearances. The ultrastructural

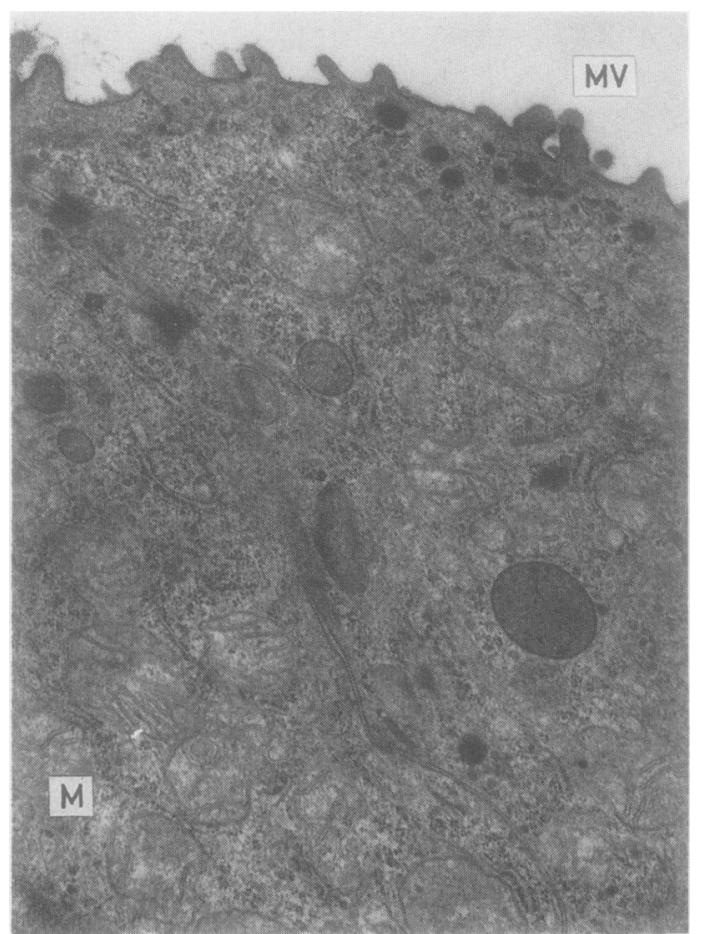

Fig 7 In type IV polyp cells sparse microvilli (MV) are irregularly arranged and variable in length and width. Terminal web is not observed clearly. Development of interdigitations is poor. Cytoplasm contains many oval mitochondria (M) and numerous free ribosomes.

characteristics of types III and IV polyps and adenocarcinoma are shown diagrammatically in fig 9.

Nuclear bodies were observed in both types III and IV polyps and carcinomas. To provide further distinction between type III and type IV polyps, the prevalence of cells containing nuclear bodies was investigated in these polyps as well as in adenocarcinomas and normal gastric mucosae (surface mucous cells). The prevalence was calculated as the number of cells containing nuclear bodies in cells divided by the total number of cells examined. For this calculation only electron micrographs of nuclei cut as nearly as possible through the centre were used. The result is shown in table 2 and analysed by Welch's method.

An average of $9 \cdot 1 \%$ of normal surface mucous cells contained nuclear bodies. The frequency range for type III polyps ranged between 3.3 and $31.7 \%$. The average was $13.9 \%$, but there was no significant difference from the normal surface mucous cell.

The average prevalence in type IV polyps was $25 \cdot 3 \%$ and that of adenocarcinoma was $32 \cdot 9 \%$. Both 


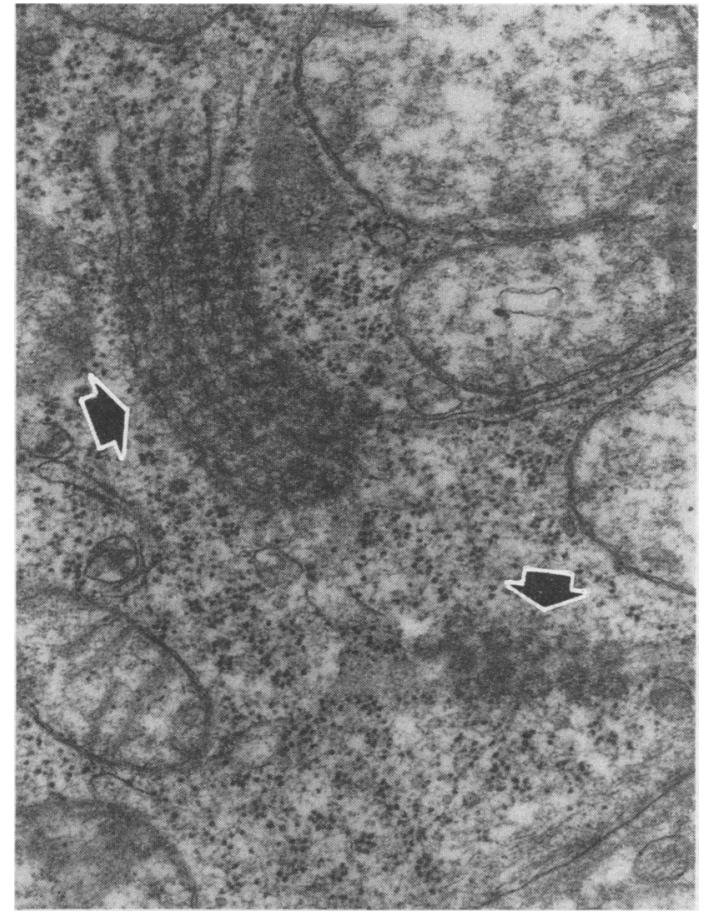

Fig 8 Annulate lamellae in a carcinoma cell (arrows). type IV polyps and adenocarcinoma showed a higher prevalence than normal gastric mucosa $(p<0.01)$. The prevalence in type III polyps was significantly lower than that of adenocarcinomas $(\mathrm{p}<0.01)$. There was no significant difference, however, between type III and type IV polyps, nor between the type IV polyps and adenocarcinoma. The prevalence of cells containing nuclear bodies in normal gastric mucosa, types III and IV polyps, and adenocarcinomas increases gradually from normal gastric mucosa to adenocarcinoma (table 2).

\section{Discussion}

In 1926 Borrmann ${ }^{9}$ and in 1928 Konjetzny ${ }^{10}$ provided early descriptions of different types of gastric polyp. Subsequently many other authors ${ }^{11-13}$ classified gastric polyps on the basis proposed by Borrmann and Konjetzny. In 1951 Walk $^{14}$ reported two cases and analysed a further 51 published examples of villous tumour or cauliflower-like papilloma of the stomach. He indicated that these should be distinguished from the common gastric polyp because of their increased malignant potential. In Monaco's series ${ }^{15}$ three sessile polyps similar to adenoma of the colon and 10 polyps composed of highly dysplastic epithelium were included in the total group of 153 gastric polyps.

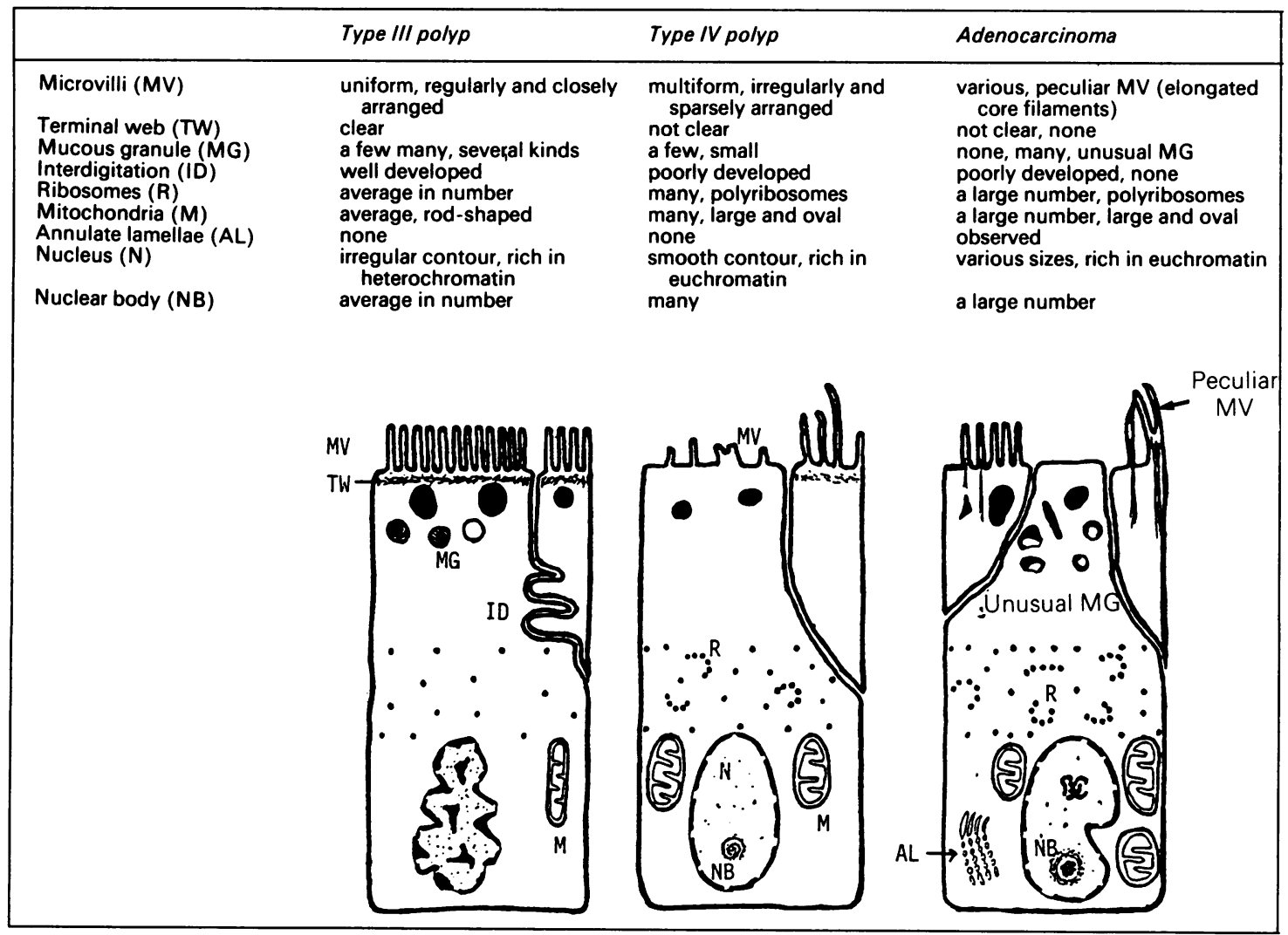

Fig 9 Ultrastructural characteristics and schemas of type III, type IV polyp, and adenocarcinoma. 
Table 2 Prevalence of cells containing nuclear bodies

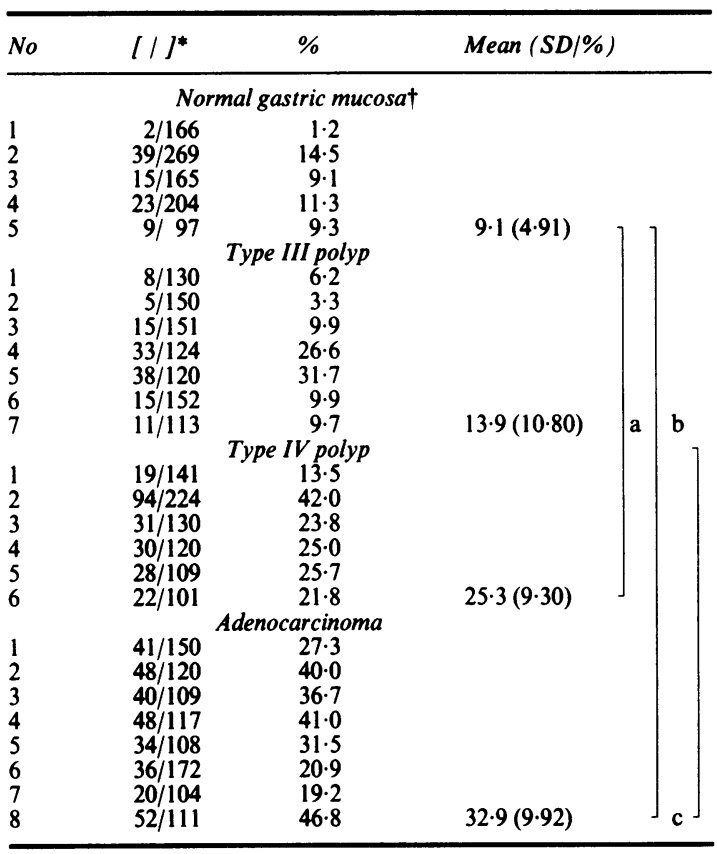

*[number of cells containing nuclear bodies/total number of cells examined]

†gastric surface mucus cells

a p < 0.01: Type IV $v$ normal gastric mucosa

b p $<0.01$ : Adenocarcinoma $v$ normal gastric mucosa

c p $<0.01$ : Type III $v$ adenocarcinoma

Ming $^{16}$ classified gastric polyps into two types: regenerative polyps and adenomatous polyps. The regenerative type had no malignant potential but the adenomatous type was neoplastic and showed a high malignant potential. His histological classification of gastric polyps has generally been accepted not only in Japan but also in Europe and the United States. These studies show that gastric polyps are not homogeneous but consist of essentially different subtypes.

Nakamura $^{2}$ divided gastric adenomas into two subtypes: type III and type IV polyps. This was on the basis of light microscopical findings alone. In this study differences between these two subtypes were shown by electron microscopy.

Dysplastic epithelial cells from type III polyps had similar appearances. Regularly arranged, uniform microvilli, rod-shaped mitochondria, well developed interdigitations and nuclei rich in heterochromatin with an irregular contour were important characteristics of these types of polyps. On the other hand, epithelial cells of type IV polyps had irregularly arranged polymorphous microvilli, poorly developed interdigitations, polyribosomes, many large oval mitochondria and nuclei rich in euchromatin with a smooth contour. According to these ultrastructural findings type IV seems to be more dysplastic and biologically active than type III.

There were many differences between type IV polyps and differentiated adenocarcinomas. Carcinoma cells did not have a uniform electron microscopic appearance. They showed obvious variations, especially in microvilli and mucous granules. Annulate lamellae, which have been reported in some malignant tumours, ${ }^{17}$ were observed only in carcinomas in this study.

The nuclear body is one of the most important ultrastructural entities in the nucleus and has been described in several types of tumour including malignant glioma $^{18}{ }^{18}$ thymoma, ${ }^{19}$ thyroid papillary adenocarcinoma, ${ }^{20}$ and cervical squamous carcinoma. ${ }^{21}$ It is thought that the nuclear body represents the nucleolus ${ }^{22}$ and is concerned with RNA synthesis. ${ }^{22}{ }^{23}$ Bouteille et al ${ }^{24}$ mentioned that nuclear bodies were related to cellular hyperactivity. There have been no systemic and comparative studies of the nuclear body in human gastric mucosa, adenoma, and carcinoma. In this study the prevalence of cells containing nuclear bodies was $13.9 \%$ in type III polyps, $25.3 \%$ in type IV, and $32.9 \%$ in adenocarcinomas. Muratani ${ }^{25}$ reported that nuclear bodies in canine gastric tumours induced by $\mathrm{N}$-ethyl- $\mathrm{N}^{\prime}$ nitro- $\mathrm{N}$-nitrosoguanidine often occurred in adenocarcinoma.

We are indebted to Professor K Kurosumi (Department of Morphology, Institute of Endocrinology, Gunma University) for his kind direction and advice in electron microscopy. We also express deep thanks to Miss M Ebara for her excellent technical assistance.

This work was supported by Grant-in-aid for Cancer Research from the Ministry of Health and Welfare (60-35) of Japan.

\section{References}

1 Nakamura T. Pathohistologische Einteilung der Magenpolypen mit spezifischer Betrachtung ihrer maligne Entartung. Der Chirurg 1970;41:122-30.

2 Nakamura T, Nakano G. Histopathological classification and malignant change in gastric polyps. $J$ Clin Pathol 1985;38:754-64.

3 Hirota T. The histology of borderline lesions of the stomach. Saishin-Igaku 1981;36:41-7.

4 Kato Y, Yanagisawa A, Sugano H. Borderline lesions (ATP) of the stomach. Saishin-Igaku 1981;36:21-30.

5 Nakano G, Nakamuru T. Malignant change of gastric polyps with special reference to type IV polyp. Stomach and Intestine 1975;10:369-77.

6 Taniguchi H, Ishigura S, Mishima T. Histopathological and histochemical studies on the borderline lesion of the stomach. Saishin-Igaku 1981;36:31-40. 
7 Ming S. The classification and significance of gastric polyps. In: Yardley JH, ed. International academy of pathology monograph. The gastrointestinal tract. Baltimore: The Williams \& Wilkins Company, 1977:149-75.

8 Rambourg A. An improved silver methenamine technique for the detection of periodic acid reactive complex carbohydrates with the electron microscope. J Histochem Cytochem 1967;15:409-12.

9 Borrmann R. Geschwülste des Magens. HenkeLubarsch. Handbuch $d$ spez pathol Anatomie $u$ Histologie. Bd4: Berlin, 1926:812-1052.

10 Konjetzny GE. Die Entzündung des Magens. HenkeLubarsch. Handbuch $d$ spez pathol Anatomie $u$ Histologie. Bd4: Berlin, 1928:768-933.

11 Merkel $\mathrm{H}$. Geschwülste des Magens. In: Kaufmann, ed. Spezielle Pathologische Anatomie. Berlin: W deGruyter, 1955:1019-48.

12 Reifferscheid M. Die gutartigen Tumoren des Magens und Duodenumes. Med Klin Wochen Schr 1959;54: 41-6.

13 Gieseler H. Zur Klinik u Pathologie der Magenpolypen, Langenbecks. Arch Klin Chir 1962;299:637-53.

14 Walk L. Villous tumor of the stomach. Arch Intern Med 1951;87:560-9.

15 Monaco AP, Roth SI, Castlemann B, et al. Adenomatous polyp of the stomach. A clinical and pathological study of 153 cases. Cancer 1962;15:456-66.

16 Ming S, Goleman H. Gastric polyps. A histological classification and its relation to carcinoma. Cancer 1965;18:721-6.

17 Wessel W, Bernhard W. Vergleichende elektronenmik- roskopische Untersuchung von Ehrlich und YoshidaAscitestumorzellen. J Krebsforsch 1957;62:140.

18 Robertson DM, Maclean JD. Nuclear inclusions in malignant gliomas. Arch Neurol 1965;13:287-96.

19 Henry K, Petts V. Nuclear bodies in human thymus. $J$ Ultrastruct Res 1969;27:330-43.

20 Kera K, Takeda S, Ogawa K. Nuclear bodies in the human thyroid papillary-carcinoma. J Clin Electron Microscopy 1979;12:321-32.

21 Nagao T. Ultrastructural study of nuclear bodies in the human cervical squamous carcinoma. $J$ Clin Electron Microscopy 1982;15:151-68.

22 Vagner-Capodano AM, Bouteille M, Stahl A, Lissitzky S. Nucleolar ribonucleo-protein release into the nucleoplasm as nuclear bodies in cultured thyrotropinstimulated thyroid cells: Autoradiographic kinetics. J Ultrastruct Res 1982;78:13-25.

23 Yasuzumi G, Yabumoto N, Shirai T, Nakai Y, Yasuzumi F. Functions of nuclear bodies as revealed by ultrastructural autoradiography and cytochemistry. Experimentia 1981;37:1072-3.

24 Bouteille M, Kalifat Sr, Delarue J. Ultrastructural variations of nuclear bodies in human disease. $J$ Ultrastruct Res 1967;19:474-86.

25 Muratani M. Nuclear bodies of experimental gastric tumor induced by $\mathrm{N}$-ethyl-N'-nitro-N-nitrosoguanidine in dogs. J Exp Clin Cancer Res 1983;4:407-14.

Requests for reprints to: Dr Gen-ichi Nakano, First Department of Surgery, Gunma University, School of Medicine, 3-39-22 Showa-machi, Maebashi 371, Japan. 